\title{
HEAT, MOMENTUM, AND MASS TRANSFER MEASUREMENTS IN INDIRECT AGITATED SLUDGE DRYER
}

\author{
J. H. Ferrasse, P. Arlabosse, ${ }^{*}$ and D. Lecomte \\ École des Mines d'Albi Carmaux, Campus Jarlard Rte \\ de Teillet, 81013 Albi CT Cedex 09, France
}

\begin{abstract}
Whereas indirect agitated drying has been extensively studied for granular materials, little is known in the case of pasty products. We describe an experimental set up specially designed for the investigation of drying kinetics, of heat transfer coefficient evolution, and of the mechanical torque necessary for stirring. This device was applied to municipal sewage sludge. Preliminary experiments were performed to investigate the influence of ageing of sludge on the drying kinetics. It appears that ageing does have no effect except for the first two days. The influences of the wall temperature, the stirrer speed, the dryer load and the location of the stirrer against the heated wall were studied. Three different rheological behaviors were observed during sludge drying. In particular, the sludge goes through a "glue" phase, and high levels of mechanical strain are recorded when the compact mass begins to break up. A critical stirrer speed is found within the range $4060 \mathrm{rpm}$. To shorten the drying time, it seems
\end{abstract}


better to adjust the wall temperature in accordance with the moisture content of the sludge.

Key Words: Agitation; Contact drying; Drying kinetics; Heat transfer coefficient; Mechanical strain

\section{INTRODUCTION}

Sludge is the unavoidable result of wastewater treatment, and has to be eliminated or, if possible, used as a resource. In France, up to 850,000 tons of dry matter were generated in 1998 from municipal sewage sludge (Chassande, 1998). An increase to some 1,300,000 tons of dry matter per year is expected in the year 2005 due to the higher collection rates, the reliability and efficiency of wastewater treatment plants, and introduction of new treatment methods to the water purification process, such as denitrification and dephosphatation.

In addition to this increase, European legislation is being strengthened in regard to sludge incineration and its use in agriculture. Furthermore, in the near future and after a transition period, the deposition of sludge at dump sites will be permitted only if the organic carbon content is lower than $5 \% \mathrm{w} / \mathrm{w}$; however dumping is still practiced for $25 \% \mathrm{w} / \mathrm{w}$ of sludge collected.

In this context, drying of sewage sludge represents an interesting intermediate stage common to all disposal methods, as it makes it possible to stabilize the sludge, reduce its volume (the water content of a mechanically dewatered sludge is close to $5 \mathrm{~kg}$ of water per $\mathrm{kg}$ of dry matter) and hygienize the product, if the residence time and the temperature are sufficient. Thermal drying of industrial sludge has been practiced for many decades but the developments for municipal sludge were rather confidential. In the late 1980s, interest was renewed and manufacturers, who have successfully applied their technologies to other applications (chemicals and food industry), tried to transfer existing technologies to sewage sludge. This explains why most sludge dryers are issued from standard equipment. But, adaptation of existing technologies is not straightforward, and equipment design is more a question of know-how than scientific knowledge. Among the most frequently encountered problems, the security issue is the one occurring mainly in direct dryers whereas problems linked to sludge stickiness are crucial for some indirect dryers like paddle, disk, or fluidized bed dryers. In association with stickiness, wear problems are also observed when moving parts are in contact with the sludge. However, as emphasized by 
Lowe (1995), successful experience in thermal processing of sewage sludge can be credited to few companies though only a limited number of these can claim to have dryers designed specifically for this purpose.

In Europe, technological problems and market tensions have reduced the offer of drying technologies during the past two years. For instance, the fluidized bed technology was almost discarded for sewage sludge treatment. Carrère Gée (1999) presents an inventory and a classification of drying technologies available on the market for sludge treatment. Four subgroups of indirect dryers are identified: disc dryers, paddle dryers, thin film dryers and drum dryers. Disc dryers are the most referenced, far beyond paddle dryers and thin film dryers. There are still few references for drum dryers with indirect heating systems but an increasing demand was observed in the past years probably due to their simpler design. Among direct dryers, four subgroups are also identified: rotary dryers, conveyor belt dryers, pneumatic transport dryers and other types of dryers including various types of batch dryers as well as solar dryers. Rotary dryers are the most widely used direct dryers far beyond conveyor belt dryers. The average specific energy consumption seems to be higher than that of indirect dryers. For batch dryers, smaller energy consumption is observed because the sludge is partially dried and energy recovery is high. The sludge composition, the rheological properties, and the amount of sludge play a key role in dryer selection. Nevertheless, the average residence time in direct dryers is shorter than that in the indirect ones, and the processing plants have larger capacity.

We focus our attention on contact drying technologies with agitators. They present the following advantages for sludge treatment: no pollution of the heat carrying medium, steam and odor confinement, VOC concentration and reduction of fire and explosion risks as the oxygen level is low in the dryer. Mechanical agitation continuously renews the contact surface area between the heated wall and the sludge, which is necessary to keep high heat transfer coefficient at the heated wall. Nevertheless, at a dry solids content of around $55 \% \mathrm{w} / \mathrm{w}$, the sludge goes through a "glue" phase and gets very sticky. When this glue phase appears, a strong increase of the torque needed for the stirring has been reported in industrial applications, which could damage the dryers. Therefore, the operation parameters of the pre-dryers are often set below the ones leading to this glue phase. A single stage drying to the final solids content above $90 \% \mathrm{w} / \mathrm{w}$ is performed using back-mixing of about $8590 \%$ of the dry product. Thus, in addition to the heat transfer coefficient between the heated wall of the dryer and the sludge, which is necessary for thermal design, the measurement of the torque needed for the stirring is required to complete mechanical design of the dryer.

Although extensive studies are published on drying, little is devoted to sewage sludge drying. This can stem from the fact that sewage sludge is quite 
different from other products, as it is a complex of inorganic and organic matter bound together with a high percentage of water. Most of the published work on sludge drying focuses on process kinetics during convective drying with the drying air either crossing the bed of extruded sludge (Léonard, 2000), or flowing above the sludge surface (Vaxelaire, 2000). The other scientific contributions concern the development and the optimization of new processes, like impulse dryers (Beckley and Banerjee, 1999), jet spouted beds of inert particles (Amazouz and Benali, 2000) or pulsed fluidized bed dryers (Poirier and Kudra, 1999). For indirect agitated drying of sludge, the literature is still scarce. Yamahata and Izawa (1985) studied experimentally the drying kinetics of two different types of sludge with a paddle dryer and determined the heat transfer coefficients. It was observed that polymer-conditioned sludge was easier to dry than sludge conditioned with inorganic chemicals. The state of the sludge changed from a viscous fluid to a powder with the decrease of the moisture content. Thus, a continuous dryer could be divided in two parts. In the first one, called the paste zone, the sludge is packed fully (this geometrically corresponds to the first third of the dryer) whereas, in the second part, the sludge is packed to only about half of the full volume (this geometrically corresponds to the two thirds of the dryer). An average overall heat transfer coefficient, on the order of $200260 \mathrm{~W} /\left(\mathrm{m}^{2} \mathrm{~K}\right)$, was obtained. But a much higher value, near $600 \mathrm{~W} /\left(\mathrm{m}^{2} \mathrm{~K}\right)$, was measured in the paste zone.

The bibliographic review reveals that little is known about sludge drying in general and about contact drying in particular. In order to determine some fundamental parameters for the mechanical and thermal designs of a contact dryer, we developed an experimental device to investigate the drying kinetics of municipal sewage sludge in an agitated batch dryer, the heat transfer coefficient at the heated wall, and the torque required for agitation. In this paper, we describe this experimental tool and present the preliminary results.

\section{EXPERIMENTAL SET UP}

The experimental device shown in Figure 1 consists of a $0.2 \mathrm{~m}$ diameter Teflon ${ }^{\circledR}$ cylindrical vessel screwed onto the top of some flat metallic plates, which simulate the wall of the dryer and its heating system.

In sludge contact dryers, steam or hot oil flowing inside the heating jacket around the dryer wall supplies the energy necessary for drying. Therefore, from the point of view of boundary conditions, a constant temperature is imposed. The difficulty for a suitable simulation of the industrial process is the determination of the heat transfer coefficient between steam 


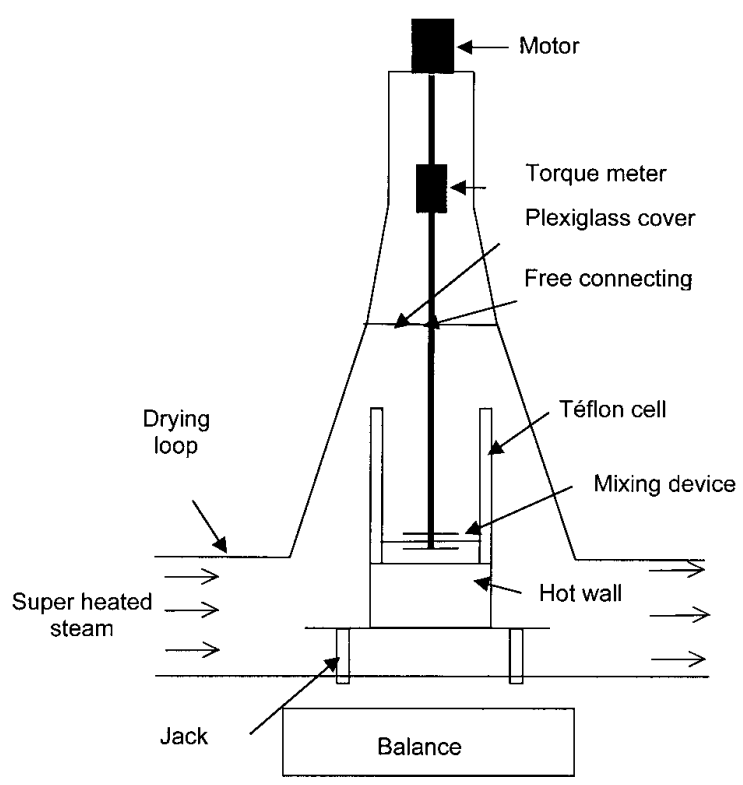

Figure 1. Batch contact dryer with agitation experimental set up.

and the interior of the wall. The system used in the laboratory scale-model consists of (Figure 2a):

a heating device made of 10 electric resistance heaters embedded into metallic plates. Each heater can supply up to $250 \mathrm{~W}$,

a $0.01 \mathrm{~m}$ thick buffer copper plate for temperature homogenization, a $0.01 \mathrm{~m}$ thick stainless steel plate, which represents the wall of the dryer.

Thermal grease is used to arrange for better contact between the plates. As the temperature of the buffer plate can be regulated, this heating system (with a constant temperature on the rear side of the wall) is quite similar to the industrial configuration. The thermal resistance between the stainless steel and copper plates could be adjusted by changing the thickness of the grease layer for instance, if the heat transfer coefficient between the wall of the dryer and the vapor or oil flowing inside is known. The Teflon vessel and the heating device lay on an iso-silicate insulator to reduce heat losses. 

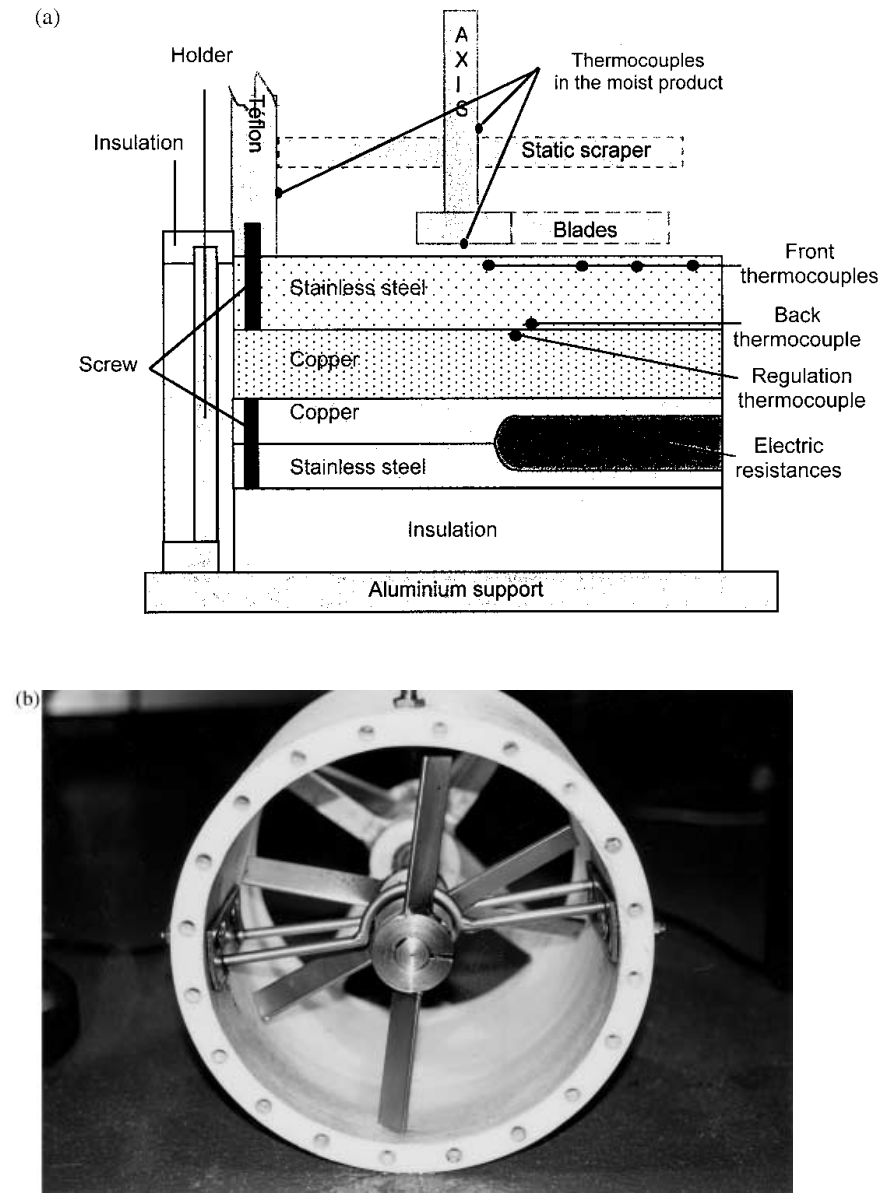

Figure 2. Detail of the heated wall of the dryer (a) and photograph of the blades and scrappers (b).

The stirring device consists of three $0.02 \mathrm{~m}$ wide and $0.16 \mathrm{~m}$ long blades, sloped at $45^{\circ}$ that are fixed to the vertical shaft (Figure 2b). The distance between two consecutive blades on the shaft is equal to $0.025 \mathrm{~m}$, and the angular misalignment $60^{\circ}$. The distance between the first blade and 
the hot wall is adjustable. A motor imparts a constant rotation speed to the stirrer. Static scrapers attached to the Teflon cell break up the sludge.

This set-up is situated in a closed drying loop in order to control the temperature, velocity and nature of the gaseous environment. Superheated steam at atmospheric pressure and $120^{\circ} \mathrm{C}$ is passed over the top of the vessel at superficial velocity less than $0.3 \mathrm{~m} / \mathrm{s}$. Under these operating conditions, the contribution of convection to the overall heat transfer for drying was negligible (Ferrasse, 2000a).

Several temperature sensors are inserted in this model dryer to measure the product and wall temperatures:

four sensors, set at $0.0015 \mathrm{~m}$ from the steel plate front side, measure the temperature at different radii $(0.015,0.055,0.075$ and $0.095 \mathrm{~m}$ ) from the center,

one sensor, set at $0.001 \mathrm{~m}$ from the steel plate rear side, measures the temperature at a radius of $0.035 \mathrm{~m}$ from the center,

one sensor, set at $0.001 \mathrm{~m}$ from the buffer copper plate front side, is used for thermal regulation,

four sensors measure the product temperatures at different heights on the stirrer shaft $(0.001,0.025,0.075$ and $0.125 \mathrm{~m}$ from the steel plate),

the last temperature sensor measures the temperature of the gaseous atmosphere just above the dryer.

The accuracy of all sensors is $\pm 0.15^{\circ} \mathrm{C}$.

A meter, which monitors the torque during drying, is incorporated into the stirrer drive. The accuracy given by the manufacturer is $\pm 0.01 \mathrm{Nm}$. All these signals, as well as the electrical power, are continuously recorded during drying. On the other hand, the weight measurement is discontinuous. For this measurement, the gaseous sweep is bypassed and the stirring device is stopped. Then, the cell is lowered onto the balance, which has an accuracy of $\pm 5 \mathrm{~g}$.

\section{DATA PROCESSING}

The heat flux $\Phi$ exchanged between the stainless steel plate and the product could be estimated either from temperature measurements or from the electrical power.

In the first case, when the steady state is reached, the heat flux can be calculated using Fourier's law in the stainless steel plate. Due to the geometric configuration, temperature gradients along the radius are quite high, even on the rear side of the steel plate. As these radial temperature gradients 
on the rear side of the steel plate are not accessible due to the dryer design, it is necessary to introduce the regulation temperature measured in the copper plate and thus to introduce the contact resistance between the steel and copper plates. To take into account the gradients on the front side of the steel plate, an effective area was assigned to each thermocouple set on the front side of the steel plate, and defined by:

$$
S_{i} \quad \pi\left[\left(r_{i}-l_{i R}\right)^{2}-\left(r_{i}-l_{i L}\right)^{2}\right]
$$

where:

$S_{i}$ is the effective area assigned to the thermocouple located at the radius $r_{i}$;

$l_{i R}$ and $l_{i L}$ are the distances, reported in Table 1, between the edges of the ring area and the position of the thermocouple.

Thus, the heat flux $\Phi$ is given by:

$$
\Phi \quad \frac{1}{d / \lambda_{\text {steel }}+R} \sum_{i}^{4}\left(T_{\text {reg }}-T_{i}\right) S_{i}
$$

where:

$d$ is the distance between the rear side of the steel plate and the position of thermocouples ( $d \quad 0.009 \mathrm{~m})$;

$R$ is the contact resistance, determined with experiments performed on water (Ferrasse 2000a). Here, $R 5 \times 10^{-4} \mathrm{~m}^{2} \mathrm{~K} / \mathrm{W}$ is used, which corresponds to a $2 \times 10^{-4} \mathrm{~m}$ thick thermal grease layer. This order of magnitude is compatible with the thickness of the grease layer experimentally arranged;

$\lambda_{\text {steel }}$ is the thermal conductivity of the stainless steel $\left(\lambda_{\text {steel }} 16\right.$ $\mathrm{W} /(\mathrm{mK})$ for ASI 4034);

Table 1. Values of the Distances Between the Right $\left(l_{i R}\right)$ or the Left $\left(l_{i L}\right)$ Edges of the Ring Area and the Position of the Thermocouple $r_{i}(\mathrm{~m})$

\begin{tabular}{ccc}
\hline$r_{i}(\mathrm{~m})$ & $l_{i R}(\mathrm{~m})$ & $l_{i L}(\mathrm{~m})$ \\
\hline 0.015 & 0.005 & 0.015 \\
0.055 & 0.010 & 0.035 \\
0.075 & 0.015 & 0.010 \\
0.095 & 0.005 & 0.005 \\
\hline
\end{tabular}


$T_{\text {reg }}$ is the regulation temperature set in the buffer copper plate; $T_{i}$ is the temperature measured near the front side of the steel plate at a radius $r_{i}$.

In the second case, the heat flux is estimated from an energy balance. The electrical power supplied by the resistances is measured and the heat losses are estimated from experiments performed with the empty setup in the same operating conditions. Thus, $\Phi$ is given by:

$$
\Phi \quad P-P_{\text {lost }}
$$

where:

$P$ is the electrical power supplied by the electrical resistances during sludge drying;

$P_{\text {lost }}$ is the electrical power supplied by the resistances when the setup is empty.

Finally, if we assume that the heat losses between the product and the Teflon cylinder are negligible, $\Phi$ can be written as the sum of the accumulation heat flux in the product and of the evaporative one. Thus, the evaporating flow rate per unit surface can be determined by:

$$
m \frac{\Phi-\Phi_{a}}{\Delta H\left(X, T_{\mathrm{s}}\right) S}
$$

where:

$\Delta H\left(X, T_{s}\right)$ is the total heat of desorption (Ferrasse, 2000b), which is a function of the moisture content $X$ and the sludge temperature $T_{\mathrm{s}}$;

$\Phi_{\mathrm{a}}$ is the accumulation heat flux in the product;

$S$ is the surface area of the stainless steel plate.

Therefore, the mass loss during drying is calculated as follows:

$$
m(t) \quad m_{\text {init }}-\int_{0}^{t} m S d t
$$

where $m_{\text {init }}$ is the initial mass in the dryer.

The mean heat transfer coefficient between the heated wall and the product is given by:

$$
h \frac{\Phi}{S\left(T_{\mathrm{w}}-T_{\mathrm{s}}\right)}
$$

where $T_{\mathrm{w}}$ is the mean wall temperature.

As the knowledge of the heat flux $\Phi$ is fundamental to the determination of the drying kinetics and the heat transfer coefficients, the calculation 


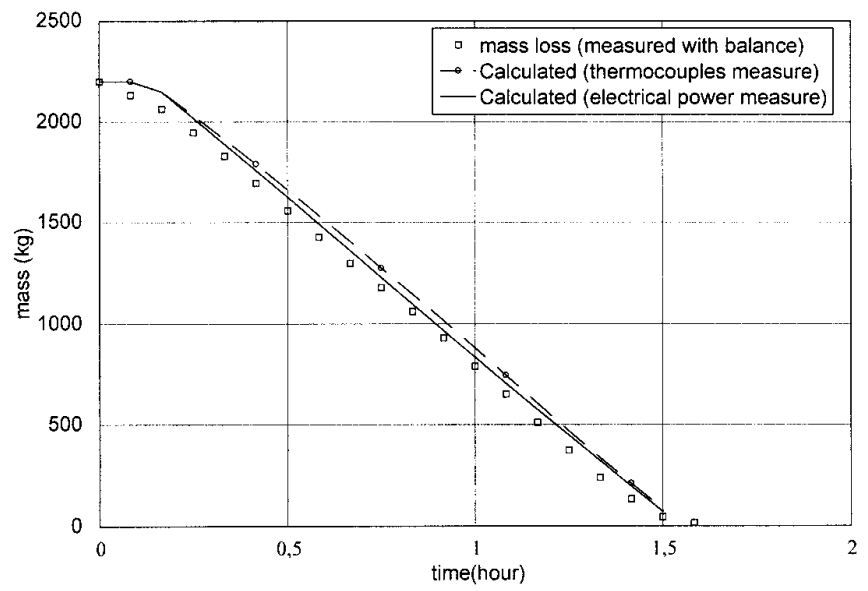

Figure 3. Comparison between three procedures used for determining the mass loss during drying of $2.2 \mathrm{~kg}$ of water, with a regulation temperature of $160^{\circ} \mathrm{C}$, and a stirring speed of $20 \mathrm{rpm}$.

procedure has been validated with experiments performed on distilled water. In operating conditions close to those used for sludge drying (a regulation temperature of $160^{\circ} \mathrm{C}$ and a stirring speed of $20 \mathrm{rpm}$ ), $2.2 \mathrm{~kg}$ of water was introduced in the batch dryer. During this experiment, the electrical power and the temperature variations were continuously recorded. The heat flux given to the product was calculated using Eqs. (2) and (3). Then, using Eq. (5), we evaluated the mass loss with the two heat flux values. In the same time, this mass loss was measured using the balance. The comparison between these three determination procedures is presented in Figure 3. The agreement being good, we can conclude that the estimation of the heat flux is correct and that any of the three methods can be used for the determination of the drying kinetics. But as was already emphasized, the weighing procedure is discontinuous, and thus the drying kinetics in the following will be determined from electrical power measurement.

\section{EXPERIMENTAL RESULTS}

All experiments were performed using municipal sewage sludge under anaerobic digestion. The sludge is sampled after mechanical dewatering; its initial moisture content is $5.25 \mathrm{~kg}$ water $/ \mathrm{kg}$ dry matter. The sludge is 
conserved in a cold storage at $4^{\circ} \mathrm{C}$. The curve fitting is carried out by means of a commercial software.

\section{Influence of Ageing}

Before describing the results, it is necessary to investigate the influence of heterogeneity and ageing, which are parameters that can not be controlled. The same experiment was repeated with samples from two different batches. The sludge was stored at $4{ }^{\circ} \mathrm{C}$ during different periods. The operating conditions were fixed at $120^{\circ} \mathrm{C}$ for the control temperature, $60 \mathrm{rpm}$ for the stirrer speed, $1.1 \mathrm{~kg}$ for the initial mass and $0.001 \mathrm{~m}$ for the distance between the first blade and the heated wall.

The change in the moisture content according to time is plotted in Figure 4 for eight experiments. Only one experiment with a sample coming from the first batch is reported; the other ones correspond to samples coming from the second batch. If we disregard the experiments performed during the first two days after sampling, all the curves are superimposed. Thus, it seems that, after the first two days, ageing at $4^{\circ} \mathrm{C}$ in a cold store does not affect the drying curve. Furthermore, an experiment was performed for each batch in the 8th day: the results obtained with the

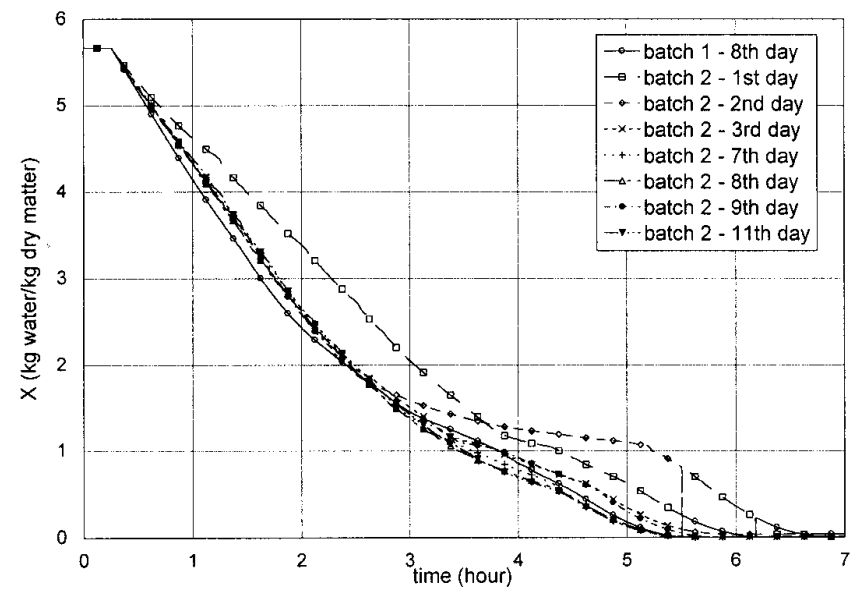

Figure 4. Influence of ageing on the evolution of the moisture content during dry ing for $120^{\circ} \mathrm{C}$ regulation temperature, $60 \mathrm{rpm}$ stirring speed, $1.1 \mathrm{~kg}$ initial mass, and $0.001 \mathrm{~m}$ distance between the first blade and the heated wall. 
sludge of batches 1 and 2 were similar. So, the heterogeneity in the sludge composition has no influence on the kinetics.

\section{Influence of Operating Conditions on Sludge Drying}

In the designed set up, several operating variables can be adjusted: temperature, stirrer speed, feed, distance between the stirrer and the heated wall, stirrer shape, and type, temperature and velocity of the gaseous field. In the present study, the stirrer shape as well as the conditions related to the gaseous sweeping were fixed. The study field was limited to the following ranges:

$$
\begin{aligned}
& 120 \leq T_{\text {reg }}\left({ }^{\circ} \mathrm{C}\right) \leq 160 \\
& 20 \leq \omega(\mathrm{rpm}) \leq 60 \\
& 1.1 \leq m_{\text {init }}(\mathrm{kg}) \leq 2.2 \\
& 0.001 \leq e(\mathrm{~m}) \leq 0.005
\end{aligned}
$$

The combined effects of these parameters make difficult the understanding of heat, mass and momentum exchanges. Accordingly, their effects on drying kinetics are examined separately.

\section{General Behavior of the Sludge During Drying}

The results obtained for the following operating conditions $T_{\text {reg }} \quad 120^{\circ} \mathrm{C}, m_{\text {init }} \quad 2.2 \mathrm{~kg}, e \quad 0.001 \mathrm{~m}$ and $\omega \quad 60 \mathrm{rpm}$ will be used to illustrate general findings. The evolution of the torque needed for stirring during the drying is presented in Figure 5 with two photographs of the sludge in the batch dryer. When the sludge is introduced in the vessel, its appearance is lumpy. After a few minutes, sludge looks like a viscous fluid, as in photograph (b). This change induces a slight decrease of the torque to its constant value. In the pasty phase, a strong withdrawal occurs and the sludge, which becomes sticky and elastic, holds the volume not agitated like the volume between the stirrer and the static scrapers. The net decrease observed around the moisture content of $2.2 \mathrm{~kg}$ water $/ \mathrm{kg}$ dry matter corresponds to a physical state where the sludge stays still and looks dry. This indicates a transition toward, what we call, the 'lumpy phase'. First, the sludge expands and the different parts agglomerate to form a single compact mass, which rolls around the dryer. As can be seen in photograph (a), only a small part of the heated wall is covered by the sludge. This is probably due to the vertical design of the dryer, in which the sludge is not 


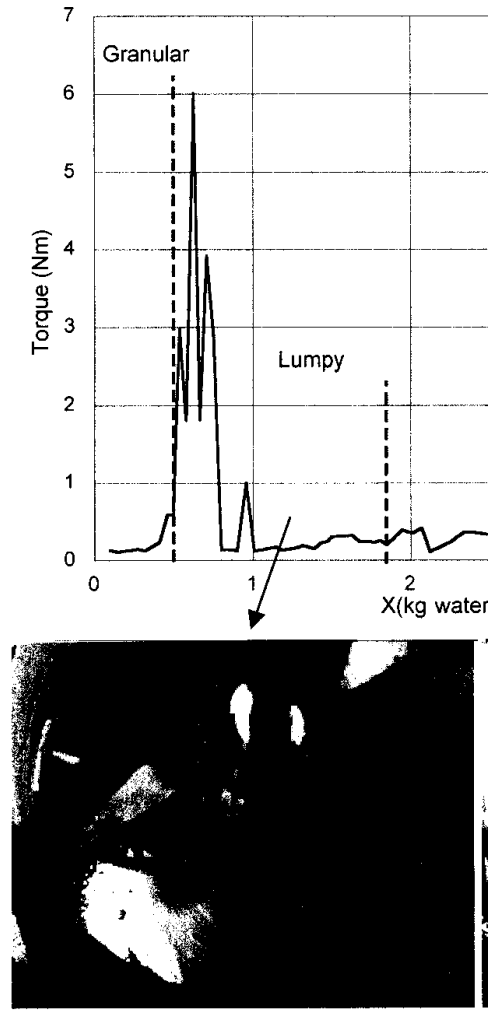

(a) Lumpy Phase

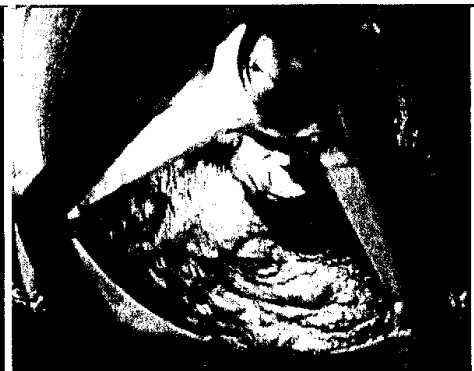

(b) Pasty Phase

Figure 5. Evolution of the torque during drying and photographs of the sludge in the dryer in the pasty and lumpy phases for $120^{\circ} \mathrm{C}$ regulation temperature, $20 \mathrm{rpm}$ stirring speed, $2.2 \mathrm{~kg}$ initial mass, and $0.001 \mathrm{~m}$ distance between the first blade and the heated wall.

compressed against the heated wall. The strong increase in the torque, measured for a $0.75 \mathrm{~kg}$ water $/ \mathrm{kg}$ dry matter moisture content, corresponds to the transition between this lumpy state and the granular phase. The maximum is recorded when the compact mass begins to break up. These observations are very close to what is reported in industrial applications as this critical moisture content corresponds to a dry solid content of $57 \%$. The size 
of the final granular material depends on the stirrer speed and on the residence time.

These three stages observed visually are also illustrated by variations of heat transfer coefficient and the drying kinetics data as shown in Figures 6 and 7. At the moisture content above $4 \mathrm{~kg}$ water $/ \mathrm{kg}$ dry matter, the heat transfer coefficient is very high (close to $600 \mathrm{~W} /\left(\mathrm{m}^{2} \mathrm{~K}\right)$ ), which gives a high evaporating capacity. The recorded value is similar to those reported by Yamahata and Izawa (1985). When the sludge reaches the sticky point, the heat and mass transfers decrease considerably. It is necessary to emphasize here that the reported heat transfer coefficient in the 'lumpy phase' gives only an order of magnitude, as we took into account the total surface for the calculation: it was shown, in the previous paragraph, that this surface is only partially covered by the sludge. At the transition between this lumpy phase and the granular one, the heat transfer coefficient and the evaporating capacity increase, since the compact mass begins to break up.

In all drying curves, moisture content is plotted as the abscissa: this representation conceals the effect of the drying time. The duration of the "lumpy phase" is the longest one. For example, durations related to Figure 6 are one hour and half for the pasty phase, seven hours for the lumpy phase, and two hours for the granular phase.

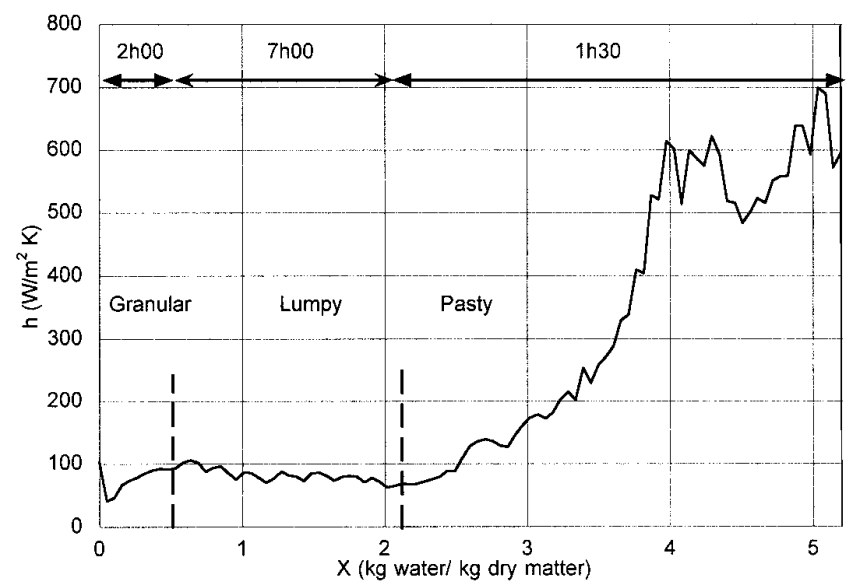

Figure 6. Evolution of the heat transfer coefficient between the heated wall and the sludge during drying for $120^{\circ} \mathrm{C}$ regulation temperature, $20 \mathrm{rpm}$ stirring speed, $2.2 \mathrm{~kg}$ initial mass, and $0.001 \mathrm{~m}$ distance between the first blade and the heated wall. 


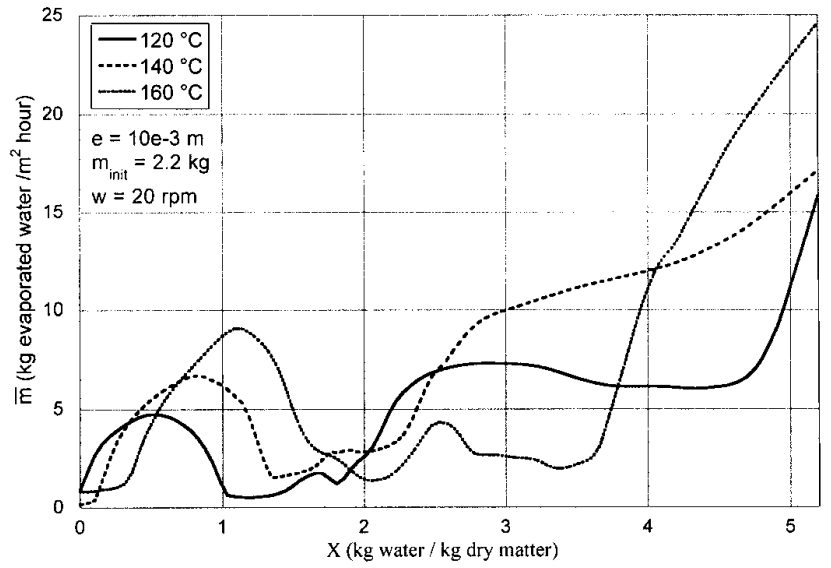

Figure 7. Influence of the regulation temperature on the drying kinetics for $20 \mathrm{rpm}$ stirring speed, $2.2 \mathrm{~kg}$ initial mass, and $0.001 \mathrm{~m}$ distance between the first blade and the heated wall.

\section{Influence of the Regulation Temperature}

The effect of temperature on the evaporating capacity is presented in Figure 7. This factor has a great influence on the drying kinetics. When the regulation temperature is high, the evaporating capacity in the first drying phase is higher. But the transition toward the 'lumpy phase' and after toward the granular phase appears sooner. The duration of the second phase, which is restrictive for the heat transfer, is longer when the regulation temperature is high. For the control of an industrial process, it would be interesting to adjust this temperature in accordance with the moisture content of the product in order to reduce the total drying time.

\section{Influence of the Stirrer Speed}

As shown in Figure 8, an increase in the stirrer speed induces an increase in the evaporating capacity. But it seems that a critical speed exists. Further increase does not change any more the mass transfer, as seen in Figure 8, and on experiments, not shown here, with an increase of the stirrer speed up to $100 \mathrm{rpm}$. This critical value seems to be around $4060 \mathrm{rpm}$. Gevaudan (1989) reported a similar result for organic granular 


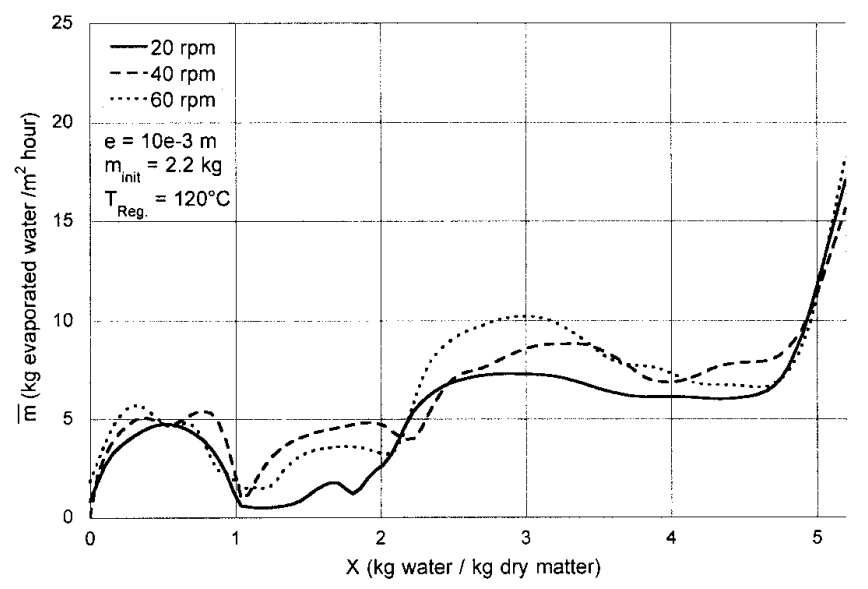

Figure 8. Influence of the stirrer speed on the drying kinetics for $120^{\circ} \mathrm{C}$ regulation temperature, $2.2 \mathrm{~kg}$ initial mass, and $0.001 \mathrm{~m}$ distance between the first blade and the heated wall.

materials, and the critical value was $42 \mathrm{rpm}$ for a dryer size close to the one used in this study.

\section{Influence of the Dryer Feeding Rate}

Two different values of initial mass $(1.1 \mathrm{~kg}$ and $2.2 \mathrm{~kg})$ were used to investigate the influence of the dryer load on the drying kinetics. The results are reported in Figure 9. During the pasty phase, the initial mass has no influence on the drying kinetics and in the two other phases, its influence is negligible. The slight difference could certainly be awarded to the wall recovery rate, since in the lumpy and granular phase, the heated wall is partially in contact with the product. And the more the dryer is loaded, the greater the contact surface is. The investigated range is probably too narrow to see the influence of this parameter on the drying kinetics.

\section{Influence of the Distance Between the Stirrer and the Heated Wall}

As with the control temperature, the influence of this parameter on the drying kinetics is very important. Only two different values 


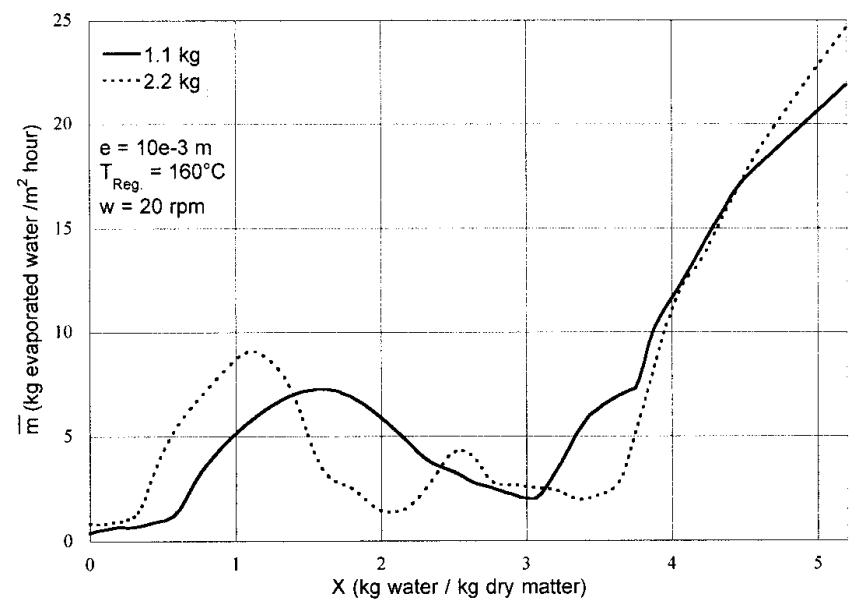

Figure 9. Influence of the initial mass on the drying kinetics for $20 \mathrm{rpm}$ stirring speed, $160^{\circ} \mathrm{C}$ regulation temperature, and $0.001 \mathrm{~m}$ distance between the first blade and the heated wall.

$(0.001$ and $0.005 \mathrm{~m})$ were used in the present study. The results are presented in Figure 10. The drying kinetics are quite different depending on this distance. The evaporating capacity is much smaller when the distance is larger. It can also be noticed on the dotted curve that the transition between pasty and lumpy phases does not appear clearly: the presence of a stationary sludge layer, between the stirrer and the heated wall, creates a dry zone near the heated wall, which reduces the heat and mass transfer. This thermal resistance increases at higher control temperatures.

\section{CONCLUSIONS}

The drying kinetics can be divided into three distinct phases. During the first phase, the sludge looks like a viscous fluid and, during drying, a rapid evaporation is observed. After a short transition period, the sludge expands and forms a compact mass, which is called the "lumpy phase". The change between this lumpy phase and the final granular phase is represented by a strong increase of the torque needed for stirring, on the order of twenty times the value measured during the pasty phase. The second phase was identified as the restrictive one for heat transfer since the sludge is only 


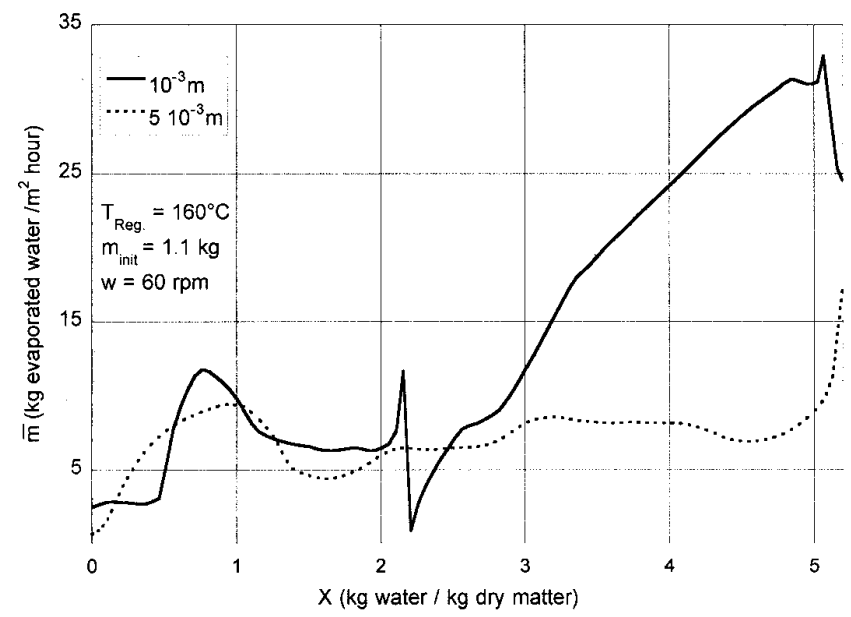

Figure 10. Influence of the distance between the first blade and the heated wall on the drying kinetics for $60 \mathrm{rpm}$ stirring speed, $160^{\circ} \mathrm{C}$ regulation temperature, and $1.1 \mathrm{~kg}$ initial mass.

partially in direct contact with the heated wall. Furthermore, its duration is much longer than those of the two other phases.

Ageing was found to have a negligible influence on the drying kinetics when the experiments are performed with sludge stored at $4^{\circ} \mathrm{C}$ more than two days. The dryer load has no influence on the kinetics, at least in the range of the selected operating conditions.

The three other factors, the location of the stirrer, the regulation temperature and the stirrer speed affect the drying kinetics. When the distance between the first blade and the heated wall is increased, a stationary sludge layer is formed on the heated wall. When this layer dries, the high thermal resistance reduces the heat and mass transfer and induces longer drying times. Thus, the first blade should be located as close as possible to the heated wall. An increase of the regulation temperature reduces the drying time, since the heat and mass transfer coefficients are increased. However, the 'lumpy phase' appears sooner and lasts longer when the wall temperature is high. So, for optimization of the industrial process, it seems to be important to adjust the wall temperature in accordance with the moisture content. Finally, a critical stirrer speed was found in between 40 and $60 \mathrm{rpm}$, although a precise range should be determined in future experiments. 
As shown in this paper, the rheological characteristics of sludge play a key role in mechanically stirred drying. Our present work concerns the measurement of the evolution of sludge viscosity with the moisture content and the analysis of the influence of the stirrer geometry on the mechanism of heat transfer during drying. The designed experimental set up reproduces at least qualitatively the general tendencies observed in the industrial process. The next step is to verify if the results are quantitatively the same. Finally, the interaction between the studied factors should be understood, as for instance the interaction between the location of the stirrer against the heated wall and the wall temperature.

\section{NOMENCLATURE}

$d \quad$ Distance between the rear side of the steel plate and the position of the front thermocouples (m)

$h \quad$ Mean heat transfer coefficient $\left(\mathrm{W} /\left(\mathrm{m}^{2} \mathrm{~K}\right)\right)$

$e \quad$ Distance between the stirrer and the wall $(\mathrm{m})$

$l \quad$ Distance between the edges of the ring area and the position of the front thermocouple $(\mathrm{m})$

$m \quad$ Mass loss $(\mathrm{kg})$

$m \quad$ Evaporating flow rate per unit surface

$P \quad$ Electrical power $(\mathrm{W})$

$r \quad$ Radius (m)

$R \quad$ Thermal resistance $\left(\mathrm{Km}^{2} / \mathrm{W}\right)$

$S \quad$ Surface area $\left(\mathrm{m}^{2}\right)$

$T \quad$ Temperature $\left({ }^{\circ} \mathrm{C}\right)$

$t \quad$ Time (h)

$X \quad$ Moisture content ( $\mathrm{kg}$ water $/ \mathrm{kg}$ dry matter)

\section{Greek Symbols}

$\begin{array}{ll}\Delta H & \text { Total heat of desorption }(\mathrm{J} / \mathrm{kg}) \\ \lambda & \text { Thermal conductivity }(\mathrm{W} /(\mathrm{mK})) \\ \Phi & \text { Heat flux }(\mathrm{W}) \\ \omega & \text { Stirrer speed }(\mathrm{rpm})\end{array}$

\section{Index}

$\begin{array}{ll}\text { a } & \text { Accumulation } \\ i & \text { Radial position } \\ \text { init } & \text { Initial }\end{array}$




$\begin{array}{ll}L & \text { Left } \\ R & \text { Right } \\ \text { reg } & \text { Regulation } \\ \mathrm{s} & \text { Sludge } \\ \mathrm{w} & \text { Wall }\end{array}$

\section{REFERENCES}

Amazouz, M.; Benali, M. Thermal Processing of Meat Rendering Sludge in a Jet Spouted Bed of Inert Particles: Effect of Additives. Proceedings of the 12th International Drying Symposium, IDS'00, Elsevier Science: Amsterdam, Paper \#418, 2000.

Beckley, J.; Banerjee, S. Operational Issues with Impulse Drying Sludge, Wat. Sci. Tech. 1999, 40(11 12), 163168.

Carrère Gée, C. Etude Du Séchage Indirect d'une Fine Couche de Boue d'hydroxyde d'aluminium en ébullition; Application au Cylindre Sécheur, PhD Thesis, University Paul Sabatier of Toulouse III, 1999.

Chassande, C. La Nouvelle Réglementation Relative à l'épandage des Boues de Stations d'épuration Urbaines en Agriculture, Proceedings of the Conference "Les Boues de Stations d'épuration Biologiques", Pollutec 98, Lyon (France) 1998.

Ferrasse, J.H. Développement d'outils Expérimentaux Pour le Dimensionnement de Procédés de Séchage Conductif Avec Agitation: Application à des Boues de Stations d'épuration Urbaines, PhD Thesis, University Paul Sabatier of Toulouse III, 2000a.

Ferrasse, J.H.; Arlabosse, P.; Lecomte, D. Direct Total Heat of Sorption Measurement from Coupled TGA-DSC Analysis, 2nd Pacific Basin Conference on Adsorption Science and Technology, Brisbane, May 2000, 2000b, 366370.

Gevaudan, A. Etude du Séchage Par Contact de Milieux Granulaires Agités: Application à l'opération de Cuisson-Séchage du Manioc, PhD Thésis, Institut National des Sciences Appliquées de Lyon. 1989.

Léonard, A.; Crine, M. Relation Between Convective Drying Kinetics and Shrinkage of Wastewater Treatment Sludges, Proceedings of the 12th International Drying Symposium, IDS'00, Elsevier Science, Amsterdam, 2000, Paper \#131.

Lowe, P. Developments in the Thermal Drying of Sewage Sludge. J. CIWEM 1995, 9, pp. 306316.

Poirier, M.G.; Kudra, T. Séchoir à Lit Fluidisé Pulsé: Fonctionnement et Applications, IV ${ }^{\mathrm{e}}$ Colloque Interuniversitaire Franco-Québecois, Montréal, 2527 Mai 1999, 7780. 
Vaxelaire, J.; Bongiovanni, J.M.; Mouques, P.; Puiggali, J.R. Thermal Drying of Residual Sludge, Wat. Res. 2000. 34(17), 43184323.

Yamahata, Y.; Izawa, H. Experimental Study on Application of Paddle Dryers for Sludge Cake Drying. Proceedings of the 4th International Drying Symposium, IDS'84, Kyoto, 1985, 719724. 